\title{
Spray-Induced Gene Silencing as a Potential Tool to Control Potato Late Blight Disease
}

\author{
Pruthvi B. Kalyandurg, ${ }^{1}$ Poorva Sundararajan, ${ }^{1}$ Mukesh Dubey, ${ }^{2}$ Farideh Ghadamgahi, ${ }^{1,3}$ Muhammad Awais Zahid, ${ }^{4}$ \\ Stephen C. Whisson, ${ }^{5}$ and Ramesh R. Vetukuri ${ }^{1, \dagger}$ \\ ${ }^{1}$ Department of Plant Breeding, Horticum, Swedish University of Agricultural Sciences, Lomma 234 22, Sweden \\ ${ }^{2}$ Department of Forest Mycology and Plant Pathology, Uppsala Biocenter, Swedish University of Agricultural Sciences, Uppsala 75651, \\ Sweden \\ ${ }^{3}$ Department of Crop Protection, Faculty of Agriculture, Ferdowsi University of Mashhad, 9177948978 Mashhad-Iran, Iran \\ ${ }^{4}$ Department of Plant Protection Biology, Swedish University of Agricultural Sciences, Lomma 234 22, Sweden \\ ${ }^{5}$ Cell and Molecular Sciences, The James Hutton Institute, Invergowrie, Dundee DD2 5DA, Scotland \\ Accepted for publication 8 May 2021.
}

\begin{abstract}
Phytophthora infestans causes late blight disease on potato and tomato and is currently controlled by resistant cultivars or intensive fungicide spraying. Here, we investigated an alternative means for late blight control by spraying potato leaves with double-stranded RNAs (dsRNA) that target the $P$. infestans genes essential for infection. First, we showed that the sporangia of $P$. infestans expressing green fluorescent protein (GFP) can take up in vitro synthesized dsRNAs homologous to GFP directly from their surroundings, including leaves, which led to the reduced relative expression of GFP. We further demonstrate the potential of spray-induced gene silencing (SIGS) in controlling potato
\end{abstract}

ABSTRACT late blight disease by targeting developmentally important genes in $P$. infestans such as guanine-nucleotide binding protein $\beta$-subunit (PiGPB1), haustorial membrane protein (PiHmp1), cutinase (PiCut3), and endo-1,3(4)- $\beta$-glucanase (PiEndo3). Our results demonstrate that SIGS can potentially be used to mitigate potato late blight; however, the degree of disease control is dependent on the selection of the target genes.

Keywords: climate change, disease control, host parasite interactions, oomycetes, pest management
Despite causing devastating late blight disease on tomato and potato worldwide, there are few alternatives to plant resistance or chemical control for the plant pathogenic oomycete, Phytophthora infestans (Kamoun et al. 2015). Given that $P$. infestans is a fast-spreading, highly adaptable filamentous pathogen, traditional breeding for resistance has not proved durable in the field (Leesutthiphonchai et al. 2018; Whisson et al. 2016). One of the most effective methods available for late blight control is intensive fungicide spraying, which costs billions of dollars to potato and tomato growers annually, and also raises serious environmental concerns. Moreover, $P$. infestans has overcome resistance to some of the fungicides in use (Schepers et al. 2018). Many countries have increased the stringency of regulations governing approval of agrochemicals, potentially limiting the selection of effective fungicides available. There is thus an urgent need to develop alternative means for pathogen control.

\footnotetext{
${ }^{\dagger}$ Corresponding author: R. R. Vetukuri; ramesh.vetukuri@slu.se

Pruthvi B. Kalyandurg and Poorva Sundararajan contributed equally to this work.

Funding: This work was supported by FORMAS (grants 2019-01316 and 201801420), the Swedish Research Council (grant 2019-04270), the NKJ-SNS-Dialogue Biocontrol Network (grant NKJ-SNS 06), the Carl Tryggers Stiftelse för Vetenskaplig Forskning (grant No. CTS 20:464), the Crafoord Foundation (grant 20200818), Partnerskap Alnarp (grants 1317/Trg, VO/2020, and 1353/VO/2021), Alnarp Stipendiekommitténs, and the Scottish Government Rural and Environment Science and Analytical Services Division.
}

*The $e$-Xtra logo stands for "electronic extra" and indicates that one supplementary table and three supplementary figures are published online.

The author(s) declare no conflict of interest.

(c) (1) $(\Theta)$ Copyright $(\odot 2021$ The Author(s). This is an open access article (c) ${ }_{\mathrm{BY}}$ NC No distributed under the CC BY-NC-ND 4.0 International license.
RNA interference (RNAi) is a conserved cellular defense mechanism mediated by double-stranded RNA (dsRNA) regulating protein expression through targeted destruction or modulation of mRNA molecules (Ghildiyal and Zamore 2009; Hannon 2002; Huang et al. 2019; Malone and Hannon 2009), or modification of chromatin (van Wolfswinkel and Ketting 2010). While RNAi is a fundamental cellular defense mechanism against invading pathogens, it can be exploited by introducing in vitro synthesized dsRNAs or molecules produced in planta as a crop management strategy (Huang et al. 2019), and is a promising new method for controlling plant diseases.

Plant transgene-derived artificial small RNA molecules (sRNAs) can induce gene silencing in some insect pests, nematodes, fungi, and oomycetes, a phenomenon called "host-induced gene silencing" (HIGS; Jahan et al. 2015; Nowara et al. 2010). However, the limitation associated with HIGS is the requirement for the generation of transgenic crop plants, which is a significant concern to consumers and its public acceptance is problematic in many countries. Moreover, HIGS is restricted to plants with established transformation methods, thus limiting the number of crop plants where this strategy can be applied. However, this limitation can be overcome by exogenous application of dsRNAs or sRNAs targeting pathogen genes essential for disease development. Recent studies have shown that spraying dsRNAs and sRNAs that target essential pathogen genes on plant surfaces can confer efficient and sustainable crop protection (Cai et al. 2018; Koch et al. 2016; Weiberg et al. 2013). Also called spray-induced gene silencing (SIGS), this strategy of disease control is more environmentally friendly as it leaves no chemical residues in crops and because of sequence specificity, inhibits the target organisms only.

This study aims to evaluate the potential for RNAi-based spray technologies to control late blight disease in a sustainable and environmentally benign way. As a first step to ascertain whether $P$. infestans sporangia can take up dsRNAs directly from their 
surroundings, we treated sporangia of $P$. infestans expressing green fluorescent protein (GFP-P. infestans) under control of the Ham34 promoter (Avrova et al. 2008) with in vitro synthesized dsRNAs homologous to GFP (dsRNA ${ }^{G F P}$ ). A 436-bp dsRNA fragment derived from the GFP gene was labeled by incorporating Cyanine 3-UTP (Enzo Life Sciences, East Farmingdale, NY) into in vitro synthesis (Cy3-dsRNA ${ }^{G F P}$ ) using the MEGAscript RNAi Kit (Invitrogen, Waltham, MA). GFP-P. infestans was cultured as described earlier by Vetukuri et al. (2011). Approximately $100 \mu \mathrm{l}$ of sporangia collected from 2-week-old plates were treated with $10 \mu \mathrm{g}$ of Cy3-dsRNA ${ }^{G F P}$ in a $1.5-\mathrm{ml}$ microcentrifuge tube. At 24 -h posttreatment, sporangia were washed with nuclease-free water to remove non-specific fluorescence, and GFP- $P$. infestans sporangia were imaged using an LSM 880 confocal microscope (Zeiss Microscopy,
Jena, Germany). GFP, Cy3, aniline blue, and chlorophyll were excited using lasers of 488, 561, 405, and $633 \mathrm{~nm}$, and detected at emission wavelengths of 499 to 552,570 to 624,410 to 496 , and 647 to $721 \mathrm{~nm}$, respectively. As a control, we used dsRNAs synthesized using the control template provided in the MEGAscript Kit $\left(\right.$ dsRNA $\left.^{\mathrm{Ct}}\right)$. Both Cy3-dsRNA ${ }^{\mathrm{Ct}}$ and Cy3-dsRNA ${ }^{G F P}$ were taken up by $P$. infestans sporangia (Fig. 1; Supplementary Fig. S1). Confocal microscopy revealed that the GFP fluorescence was significantly reduced or had disappeared in the majority of sporangia compared with the control dsRNA (Cy3-dsRNA ${ }^{\mathrm{Ct}}$ ) treatment (Fig. 1A). Furthermore, the sporangia that exhibited reduced GFP fluorescence also exhibited $\mathrm{Cy} 3$ fluorescence. These results suggest that the dsRNA was effectively introduced into the $P$. infestans sporangia and dsRNAs maintain their RNAi activity by silencing the target gene.
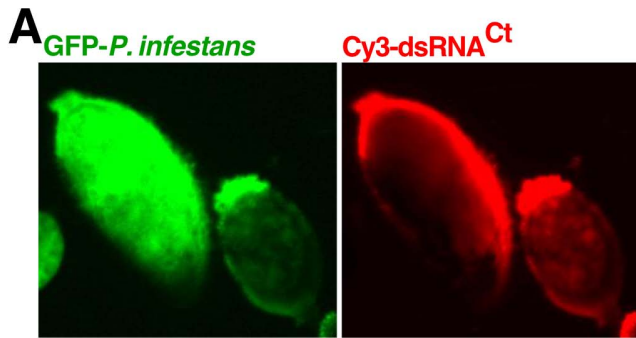

Bright field
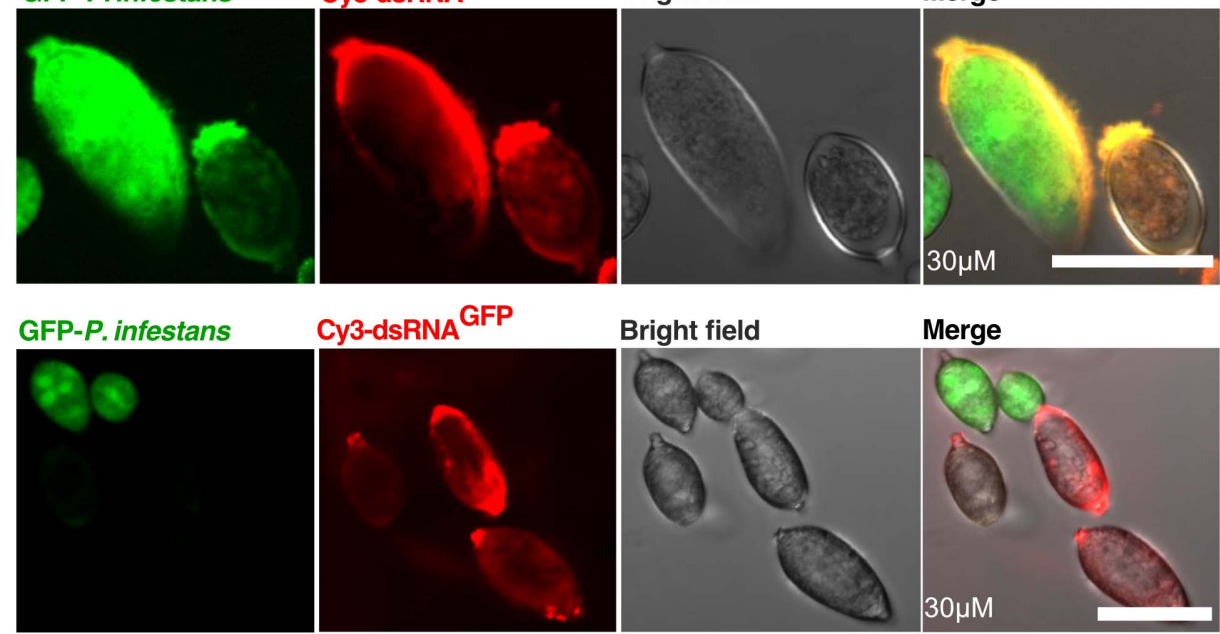

Cy3-dsRnA GFP

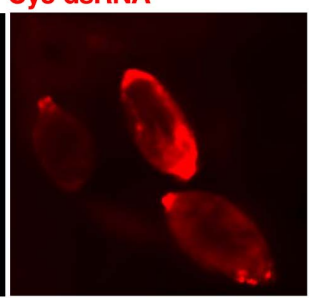

Bright field
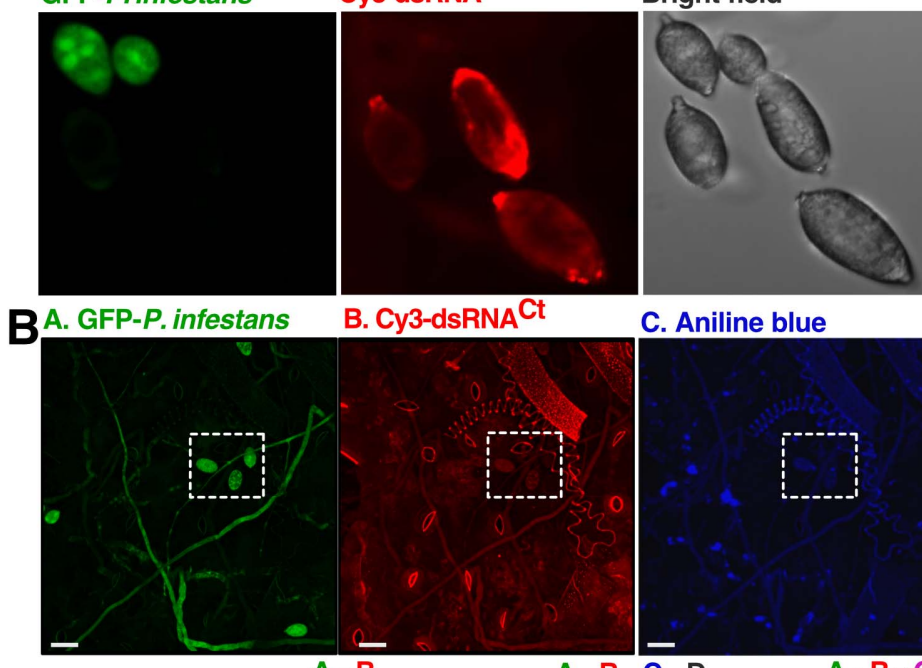

C. Aniline blue

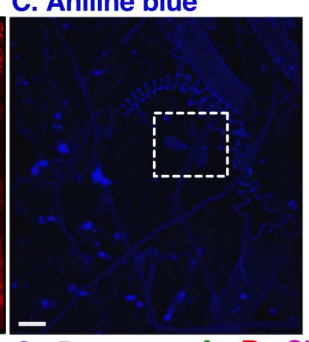

D. Bright field

Merge

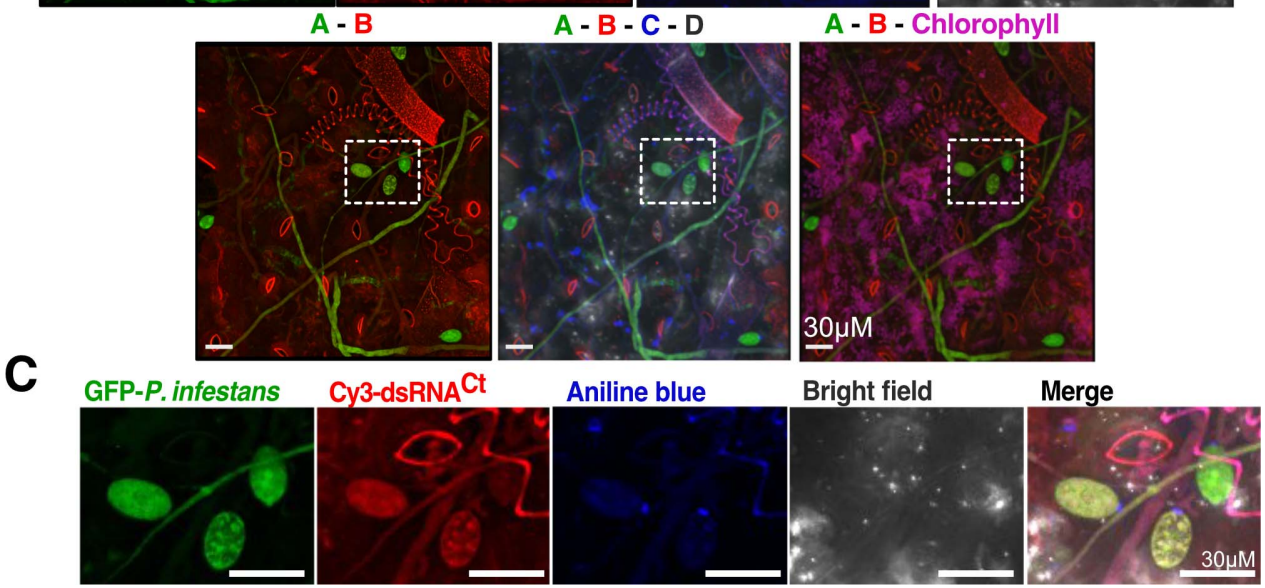

Fig. 1. dsRNA-induced gene silencing and uptake of dsRNA by Phytophthora infestans sporangia. A, Representative confocal microscopy images showing colocalization of GFP with Cy3 in Cy3-dsRNA ${ }^{\mathrm{Ct}}$-treated GFP-P. infestans sporangia (upper panel). Not all sporangia take up the Cy3-dsRNA, but reduced GFP accumulation was observed in the GFP-P. infestans sporangia that took up Cy3-dsRNA ${ }^{G F P}$ (lower panel). Sporangia were imaged 24-h posttreatment with dsRNAs. B, Representative confocal microscopy images show accumulation of Cy3-dsRNA in the hyphae and sporangia of $P$. infestans. Trichome, stomatal guard cells, and epidermal cells of potato leaf also exhibit Cy3 fluorescence. Images were taken with wavelengths corresponding to GFP, Cy3, and aniline blue stain (staining $\beta$-1,3-glucans). C, Zoomed images of the highlighted region in B, showing accumulation of Cy3-dsRNA in the sporangium. Images were taken 5 dpi of GFP-P. infestans on potato leaves. 
We then tested if $P$. infestans can take up dsRNA sprayed on potato leaves in a detached leaf assay (DLA). Potato leaves (cultivar Bintje) were locally sprayed on defined areas on the leaves with $20{\mathrm{ng} \mathrm{\mu l}^{-1} \mathrm{Cy} 3-\mathrm{dsRNA}}^{\mathrm{Ct}}$ using an automizer (Travalo Classic HD). At $24 \mathrm{~h}$ post spray application, leaves were drop-inoculated with 10 $\mu l$ of GFP- $P$. infestans sporangia $\left(5 \times 10^{4}\right.$ spores $\left.\mathrm{ml}^{-1}\right)$ and incubated in a climate-controlled chamber $\left(22^{\circ} \mathrm{C}\right.$ daytime and $20^{\circ} \mathrm{C}$ night-time temperature; $16 \mathrm{~h}$ photoperiod). At 5 days postinoculation (dpi), approximately 4- to 5-mm diameter leaf samples from the infected part of the leaf were mounted in aniline blue solution $(0.1 \%$ aniline blue in phosphate buffered saline, $\mathrm{pH} 7)$ and incubated in the dark until imaged by confocal microscopy. This demonstrated colocalization of GFP and Cy3-dsRNA ${ }^{\mathrm{Ct}}$ in P. infestans hyphae (Fig. 1B) and sporangium (Fig. 1C), indicating uptake of dsRNA $^{\mathrm{Ct}}$ by GFP-P. infestans. Aniline blue staining demonstrated that $\beta$-1,3-glucan localization in sporangia was distinct from the colocalized Cy3-dsRNA ${ }^{\mathrm{Ct}}$ and GFP (Fig. 1C). Uptake of dsRNA by fungal pathogens from the surrounding environment, including leaves, has been previously observed in several fungal pathosystems (Koch et al. 2016; Wang et al. 2016; Weiberg et al. 2013). Oomycetes, although evolutionarily different from fungi, may act similarly in the uptake of dsRNA from the external environment.
A report demonstrated that $P$. infestans dsRNA could be taken up by sporangia and cysts (Qiao et al. 2021). However, the exact mechanism of sRNA and dsRNA uptake is yet to be determined.

Having established that sporangia can take up dsRNA from the surrounding environment, we next tested if the uptake of dsRNA sprayed on host potato leaves in a DLA can silence the target $P$. infestans gene. Potato leaves were locally sprayed with either

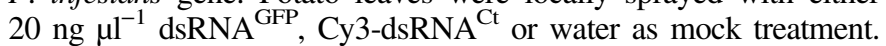
At 1 day post spray application, the leaves were drop-inoculated with GFP- $P$. infestans sporangia $\left(10 \mu \mathrm{l}\right.$ of $5 \times 10^{4}$ spores $\left.\mathrm{ml}^{-1}\right)$. Leaves were imaged at $5 \mathrm{dpi}$ in a ChemiDoc MP imaging system (BioRad Laboratories, Hercules, CA) using predefined settings for Alexa488 and Cy3 for visualizing GFP and Cy3 fluorescence, respectively. In line with the experiments on sporangia, the GFP fluorescence in leaves sprayed with dsRNA ${ }^{\text {GFP }}$ was reduced compared with Cy3-dsRNA ${ }^{\mathrm{Ct}}$ and mock-treated leaves (Fig. 2A). To confirm the visual observation, relative accumulation of GFP protein was quantified using immunoblot analysis as described in Kalyandurg et al. (2019) with anti-GFP-HRP antibody (GF28R; Invitrogen), which confirmed the observed reduction in GFP fluorescence (Fig. 2B). Additionally, real-time quantitative PCR (qRT-PCR) was used to confirm the relative expression of GFP. To that end, total RNA
GFP-P. infestans

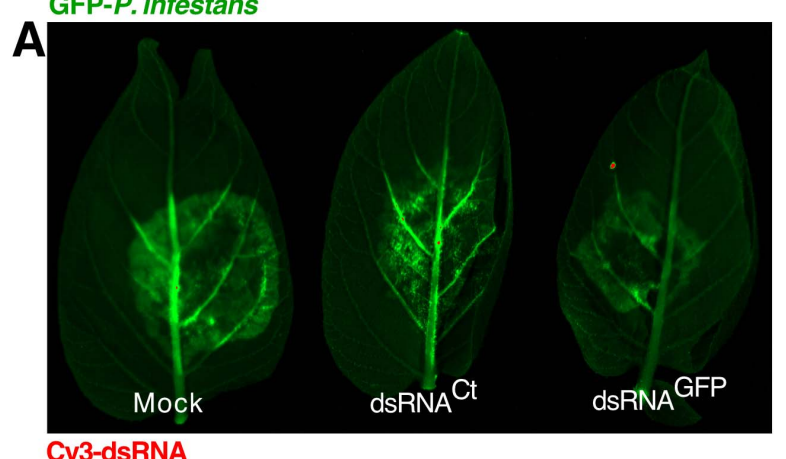

Cy3-dsRNA

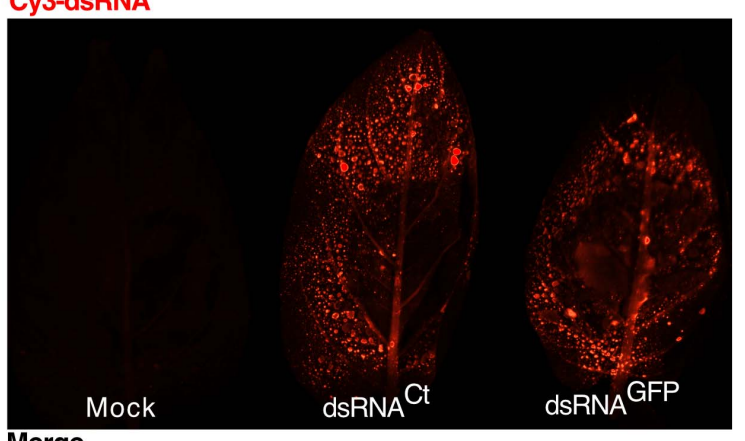

Merge

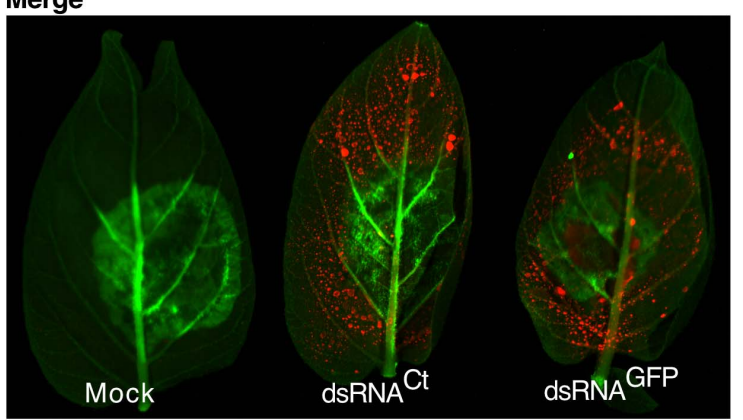

B

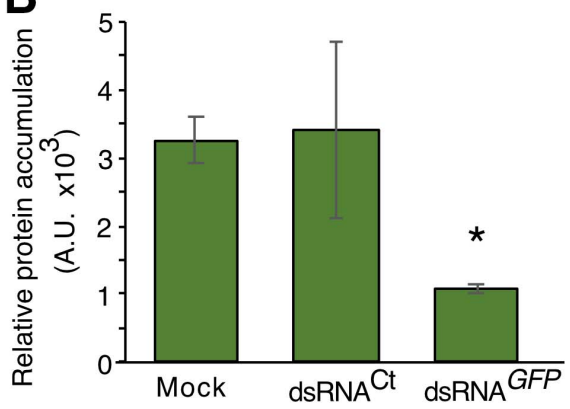

C
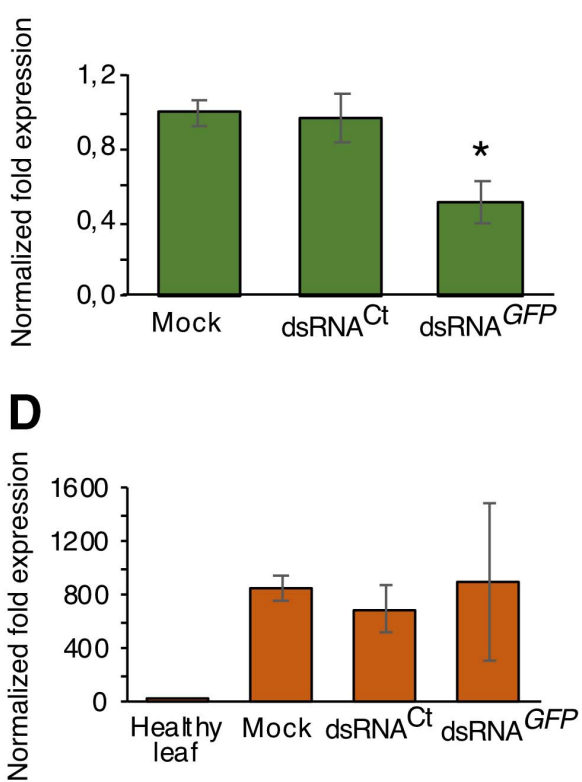

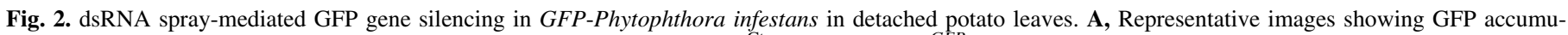

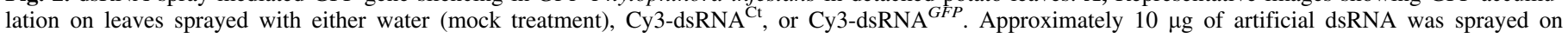

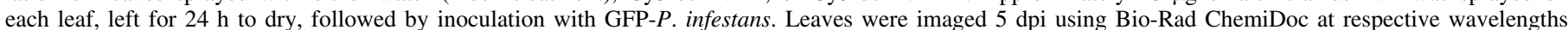

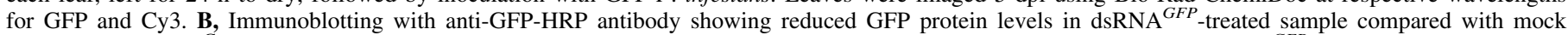

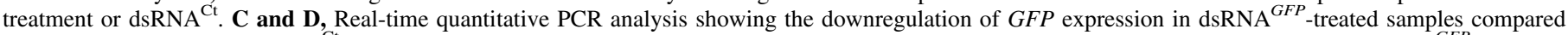

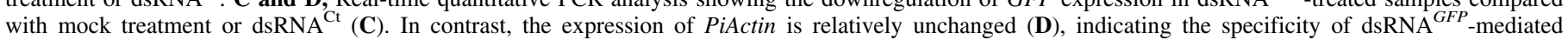
silencing. Asterisks indicate statistically significant difference relative to mock treatment control, $n=6 ;{ }^{*} P<0.01 ;$ Student's $t$ test. 
was extracted from 5 dpi of dsRNA-treated leaves (Qiagen RNeasy Plant Total RNA Extraction Kit; https://www.qiagen.com/us/) followed by DNase treatment (Ambion Turbo DNA-Free Kit; Thermo Fisher Scientific, https://www.thermofisher.com/order/ catalog/product/AM1907\#/AM1907) and cDNA synthesis (qScript SuperMix; Quantabio, https:/www.quantabio.com/qscript-cdnasupermix). Undiluted cDNA $(1 \mu \mathrm{l})$ was used as a template for qRT-PCR (DyNAmo Flash SYBR Green Kit; Thermo Fisher Scientific). The target gene transcript levels were normalized to the expression of reference gene P. infestans actin (PiActin; Vetukuri et al. 2011). Analysis revealed that the relative expression of GFP normalized to PiActin (NCBI P22131) was reduced by half in dsRNA ${ }^{G F P}$-treated leaves compared with mock and dsRNA ${ }^{\mathrm{Ct}}$-treated leaves (Fig. 2C). Notably, the relative expression of PiActin normalized to potato actin (StActin NCBI XM_006345899) remained unchanged (Fig. 2D). Taken together, these results demonstrate target-specific dsRNAmediated gene silencing.

To explore the potential of SIGS as a tool to control potato late blight disease, we targeted a variety of $P$. infestans genes either reported as or likely to be essential for pathogenesis, expressed at different stages of the infection cycle, and an agrochemical target. These genes included guanine-nucleotide binding (G) protein $\beta$-subunit (PiGPB1; PITG_06376; XP_002998508), oxysterol binding protein (PiOSBP; PITG_10462; XP_002902250), haustorial membrane protein (PiHmp1; PITG_00375; XP_002908980), cutinase (PiCut3; PITG_12361; XM_002900240), and endo-1,3(4)$\beta$-glucanase (PiEndo3; PITG_13567; XP_002899770).

PiGPB1 is associated with signal transduction during pathogenesis and is reported to be critical for proper sporangial development (Latijnhouwers and Govers 2003). Through HIGS, it was previously demonstrated that targeting PiGPB1 resulted in severe disease reduction, especially during the transition from biotrophic to the necrotrophic stage (Jahan et al. 2015). PiOSBP is the target of oxathiapiprolin, a recent agrochemical effective against Phytophthora sp. (Miao et al. 2016, 2018; Pasteris et al. 2016). Although the exact function of OSBP is not clearly established, in other eukaryotes it is suggested to play a role in membrane-mediated lipid transport and intercellular distribution of lipid molecules (Raychaudhuri and Prinz 2010).

Penetration and colonization of host tissue is paramount for successful infection by $P$. infestans. Penetration of the outer tissue primarily comprising cutin and $\beta$-1,4-glucans requires action of degradative enzymes including carbohydrate esterases such as cutinases and glycoside hydrolases such as endo- or exoglucanases, together known as carbohydrate-active enzymes or CAZymes (Brouwer et al. 2014; Ospina-Giraldo et al. 2010b). Here, we targeted two genes encoding degradative proteins PiEndo3 and PiCut3, both of which exhibit elevated transcript levels in germinating cysts (Ah-Fong et al. 2017) and thus present at the time of host tissue invasion. PiEndo3 is a glycoside hydrolase family 81 enzyme (in the database resource FungiDB; https://fungidb.org/fungidb/ app/) with potential activity on cellulose and 1,3- $\beta$-glucans, both of which may be found in P. infestans and plants (e.g., callose in plants). PiCut3 belongs to carbohydrate esterase family 5 (OspinaGiraldo et al. 2010b), but the precise importance of PiCut3 in $P$. infestans pathogenicity has not been determined. The high expression of PiCut3 during the initial stages of infection (Ospina-Giraldo et al. 2010b) suggests a role in the degradation of cutin at the outermost pathogen-plant barrier. After penetration, the membrane-associated and infection-induced PiHmp1 protein plays a critical role in the intercellular progression and host colonization of $P$. infestans (Avrova et al. 2008). Hmp1 is considered to be necessary for haustorium formation (Avrova et al. 2008), which are biotrophic pathogen structures that extend into host cells for delivery of defense-suppressing effector proteins (Boevink et al. 2020, 2011; Kagda et al. 2020).

To investigate the effect of targeted dsRNA treatments on development of $P$. infestans, detached potato leaves were sprayed with
$500 \mu \mathrm{l}$ of $20{\mathrm{ng} \mu \mathrm{l}^{-1} \mathrm{dsRNA}}^{\mathrm{Ct} / \mathrm{GFP}}$ as controls, or dsRNAs specific to the individual target genes outlined above. At $24 \mathrm{~h}$ post spray application, the leaves were drop-inoculated $\left(10 \mu \mathrm{l}\right.$ of $5 \times 10^{4}$ spores $\mathrm{ml}^{-1}$ ) with $P$. infestans isolate 88069 . At $5 \mathrm{dpi}$, trypan blue staining of the inoculated leaves was carried out to determine the progression of $P$. infestans. Briefly, leaves were incubated in trypan blue staining solution (Koch and Slusarenko 1990) for $30 \mathrm{~min}$, followed by a single wash with $100 \%$ ethanol and overnight incubation in $100 \%$ ethanol at room temperature (Fernández-Bautista et al. 2016). Leaves were then carefully transferred to a $20 \%$ glycerol solution and imaged using a scanner (V850Pro; Epson). Although normal disease progression was observed in the mock and dsRNA $^{\mathrm{Ct} / \mathrm{GFP}}$-treated leaves, $P$. infestans development was significantly inhibited in the dsRNA ${ }^{\text {PiGPBI }}{ }_{-}$, dsRNA ${ }^{\text {PiEndo } 3}{ }_{-}$, dsRNA $^{\text {PiCut }}{ }_{-}$, and dsRNA ${ }^{\text {PiHmpl }}$-treated leaves (Fig. 3A) but not in the dsRNA $^{P i O S B P}$-sprayed leaves (Supplementary Fig. S2). Quantification of the area of infection sites using the NIH software ImageJ revealed that the mean area of infection sites in the mock and control were 2.2 and $2.9 \mathrm{~cm}^{2}$, respectively. The mean area of infection sites in the dsRNA-treated samples ranged from 0.6 to $1.24 \mathrm{~cm}^{2}$, indicating a reduction in the area of infection in the DLAs (Fig. 3B). As no significant reduction in $P$. infestans growth was observed in the dsRNA ${ }^{P i O S B P}$-treated leaves (mean area of infection $=2.8 \mathrm{~cm}^{2}$; Supplementary Fig. S2), the DLAs were limited to four replications for dsRNA ${ }^{P i O S B P}$ treatment, while DLAs for each of the other targets were repeated at least five times with six leaves in each experiment $\left(n=\sim 30 ; n=24\right.$ for dsRNA $\left.{ }^{\text {PiOSBP }}\right)$. To confirm that the observed inhibition of disease progression was because of dsRNA-mediated gene silencing, the relative gene expression of the target genes in the infected dsRNA-treated leaves was quantified using qRT-PCR. Compared with the dsRNA ${ }^{\mathrm{Ct}}$-treated samples, a $\log _{2}$ fold-decrease of 2.5-, 1-, 1.5-, and 2 was observed in PiGPB1, PiHmp, PiCut3, and PiEndo3 transcript levels in each of the respective treatments, suggesting that the observed reduction in $P$. infestans disease progression was indeed a result of dsRNAmediated targeted gene silencing (Fig. 3C). In contrast, the approximately twofold decrease in PiOSBP transcript levels when treated with dsRNA ${ }^{\mathrm{OSBP}}$ was insufficient to impact on P. infestans infection (Supplementary Fig. S2).

Prior studies have noted that the formation of sporangia during 36- to 48-h postinfection is critical for the disease progression and transition from biotrophic to necrotrophic phase (Judelson and Blanco 2005). To investigate if SIGS-mediated inhibition of disease progression was also associated with defects in sporulation, we carried out a microscopic examination of disease lesions (MDG41 Stereo Microscope; Leica Microsystems, Heerbrugg, Switzerland). Our analysis revealed that treatment with dsRNA ${ }^{P i G P B 1}$ resulted in severe sporulation inhibition (Fig. 4A, B, and F) compared with the dsRNA ${ }^{\mathrm{Ct}}$ treatment. This agrees with Jahan et al. (2015) and Latijnhouwers and Govers (2003), who demonstrated the formation of fewer and deformed sporangia through silencing in hp-PiGPB1 transgenic plants and transcriptional silencing in P. infestans stable transformants, respectively. Also, in agreement with those studies, treatment with dsRNA ${ }^{P I G P B 1}$ did not appear to disrupt the germination of the sporangia or mycelial progression, as mycelia could be seen emerging from stomata (Fig. 4B).

As expected, silencing genes encoding CAZymes, Hmp1 and OSBP did not result in severe inhibition of sporulation (Fig. 4C; Supplementary Fig. S2D and E). However, the number of sporangia observed was significantly lower in the leaves treated with dsRNA $^{\text {PiEndo3 }}$ and dsRNA ${ }^{\text {PiCut3 }}$ (Fig. 4D to F), suggesting that the lower sporangial count could be as a result of reduced disease progression rather than a direct effect on the sporangial development.

$P$. infestans cell walls contain both cellulose and 1,3- $\beta$-glucan, which may be substrates for PiEndo3, potentially leading to remodeling of the wall. However, our findings do not indicate any direct effect of PiEndo3 on the growth and development of P. infestans, thus it is likely that this enzyme acts on plant polysaccharides, and 
decreased disease progression can be attributed to the silencing of PiEndo3 expression. Further analysis focused on more detailed phenotyping might be valuable in unraveling the functions of this and other $P$. infestans glucanases. Interestingly, treatment with dsRNA $^{\text {PiCut3 } 3}$ resulted in a smaller and aberrant mycelial phenotype (Fig. 4D), probably owing to erratic penetration, causing nutrient starvation. This is consistent with the expected role of cutinase in facilitating host penetration by Phytophthora species by breaking down cutin and enabling plant cell wall disintegration (OspinaGiraldo et al. 2010a; Zerillo et al. 2013).

Although disease progression was significantly lower in the dsRNA $^{\text {PiHmpl }}$-treated leaves, the number of sporangia per square centimeter was not reduced (Fig. 4C and F). These results corroborate Avrova et al. (2008), who showed that dsRNA-mediated transient silencing of PiHmpl produced a similar number of sporangia compared with the control when grown in agar culture, even though infection was suppressed compared with the control nonhomologous dsRNA-treated lines.

Our observations show that not all sporangia take up the dsRNAs to levels detectable using conjugated $\mathrm{Cy} 3$ dye. Hence, optimizing formulation of dsRNAs to facilitate dsRNA uptake will be crucial to successfully use SIGS for disease control (San Miguel and Scott 2016; Yan et al. 2020). It is also possible that spray-applied dsRNAs can enter $P$. infestans as spores germinate on the leaf surface; this is evidenced here (Fig. 1B and C) where Cy3-labeled dsRNAs can be seen labeling pathogen hyphae. A further question arises regarding the nature of the dsRNAs taken up by $P$. infestans. That is, it remains to be determined if $P$. infestans takes up
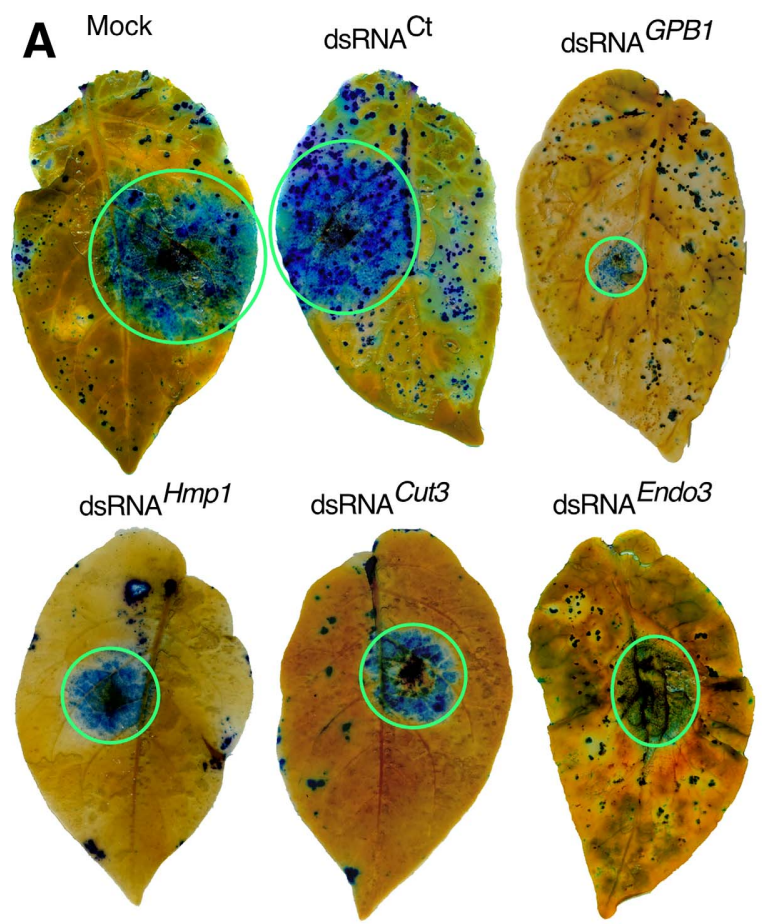

B
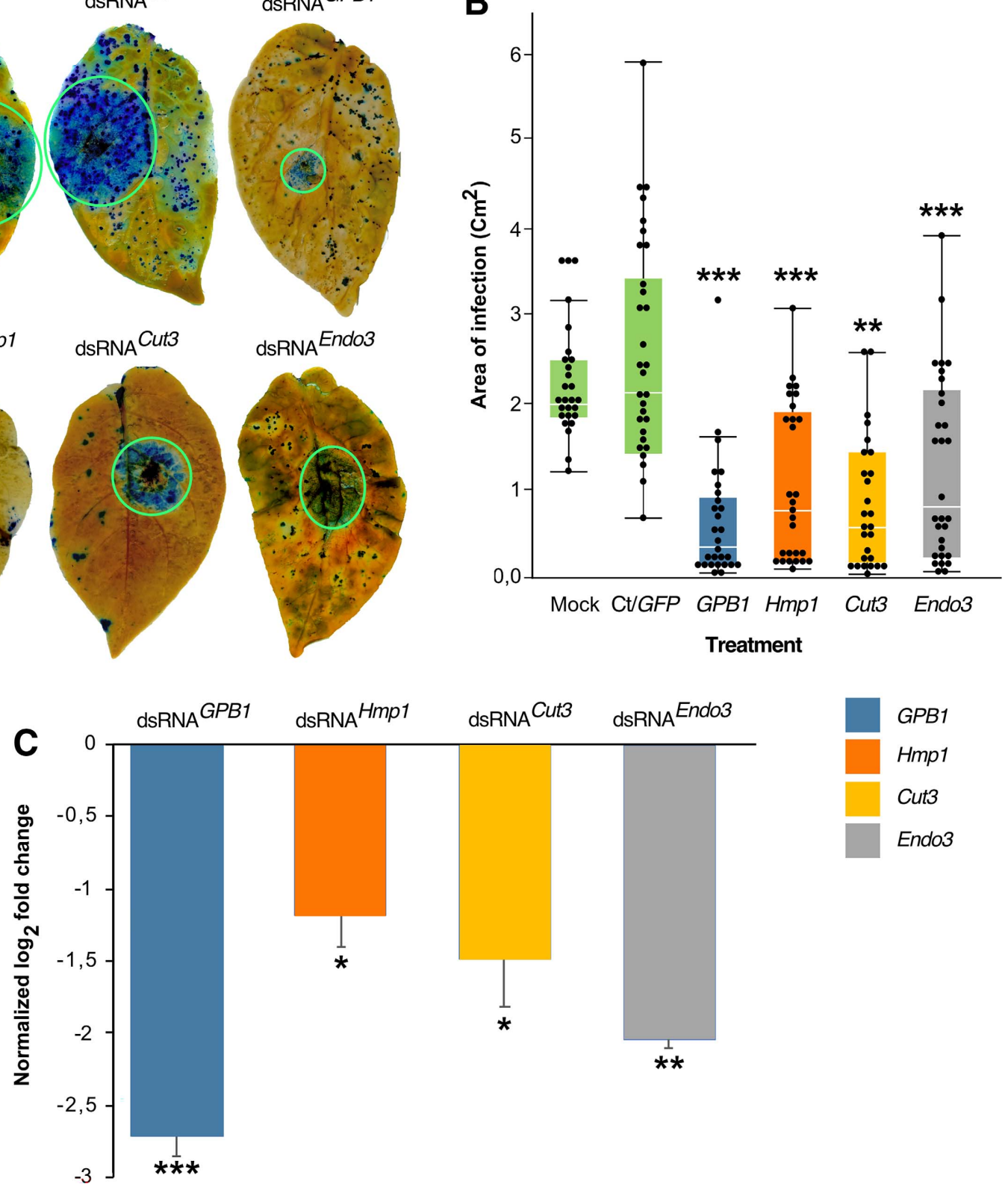

Fig. 3. Effect of spray-induced gene silencing on Phytophthora infestans disease progression. A, Representative pictures of trypan blue-stained potato leaves showing typical $P$. infestans 88069 disease progression at 5 dpi on leaves sprayed with water (mock treatment) or dsRNA ${ }^{\mathrm{Ct}}$, but reduced lesion sizes for leaves sprayed with dsRNA ${ }^{P i G P B}$ (G protein $\beta$-subunit), dsRNA ${ }^{\text {PiEndo3 }}$ (endo-1,3(4)- $\beta$-glucanase), dsRNA ${ }^{\text {PiCut3 }}$ (cutinase), or dsRNA ${ }^{\text {PiHmpl }}$ (haustorial membrane protein). B, Box plot showing the quantification of area of disease progression for each dsRNA spraying $(n=27$ to 30$)$. C, Real-time quantitative PCR analysis showing the relative gene expression of each target upon treatment with respective dsRNAs, compared with treatment with dsRNA ${ }^{C t}$. The $C q$ values of target genes were normalized to the $C q$ values of PiActin and shown as normalized $\log _{2}$ fold-change. Asterisks indicate statistically significant difference relative to mock treatment control; ${ }^{* * *} P<0.0001,{ }^{* *} P<0.001,{ }^{*} P<0.01$; Control, Dunnett's test. 
the long dsRNA molecules, or whether the gene silencing is indirect, with dsRNAs first entering plant cells where they are processed into siRNAs before entry into $P$. infestans. However, it has been shown that long dsRNAs can enter $P$. infestans protoplasts derived from hyphae (Whisson et al. 2005), so at least some of the spray-applied dsRNAs are likely to enter $P$. infestans directly.

Although dsRNA-mediated SIGS has been reported in other pathogens (Cai et al. 2018; Koch et al. 2016; Weiberg et al. 2013; Qiao et al. 2021), it is yet to be proven if this gene silencing is the result of plant RNAi machinery or the pathogen RNAi mechanism. Our analysis using confocal microscopy showed uptake of Cy3-dsRNA in the P. infestans mycelium and sporangia, and indicates that the site of dsRNA processing for RNA silencing is located in the pathogen (Fig. 1B and C). Further analysis, including sRNA sequencing from the dsRNA-sprayed leaves, could prove if the plant RNA silencing machinery is processing the sprayed dsRNAs.

The application of SIGS for $P$. infestans has recently been reported, and using some of the same genes used here, but reduced
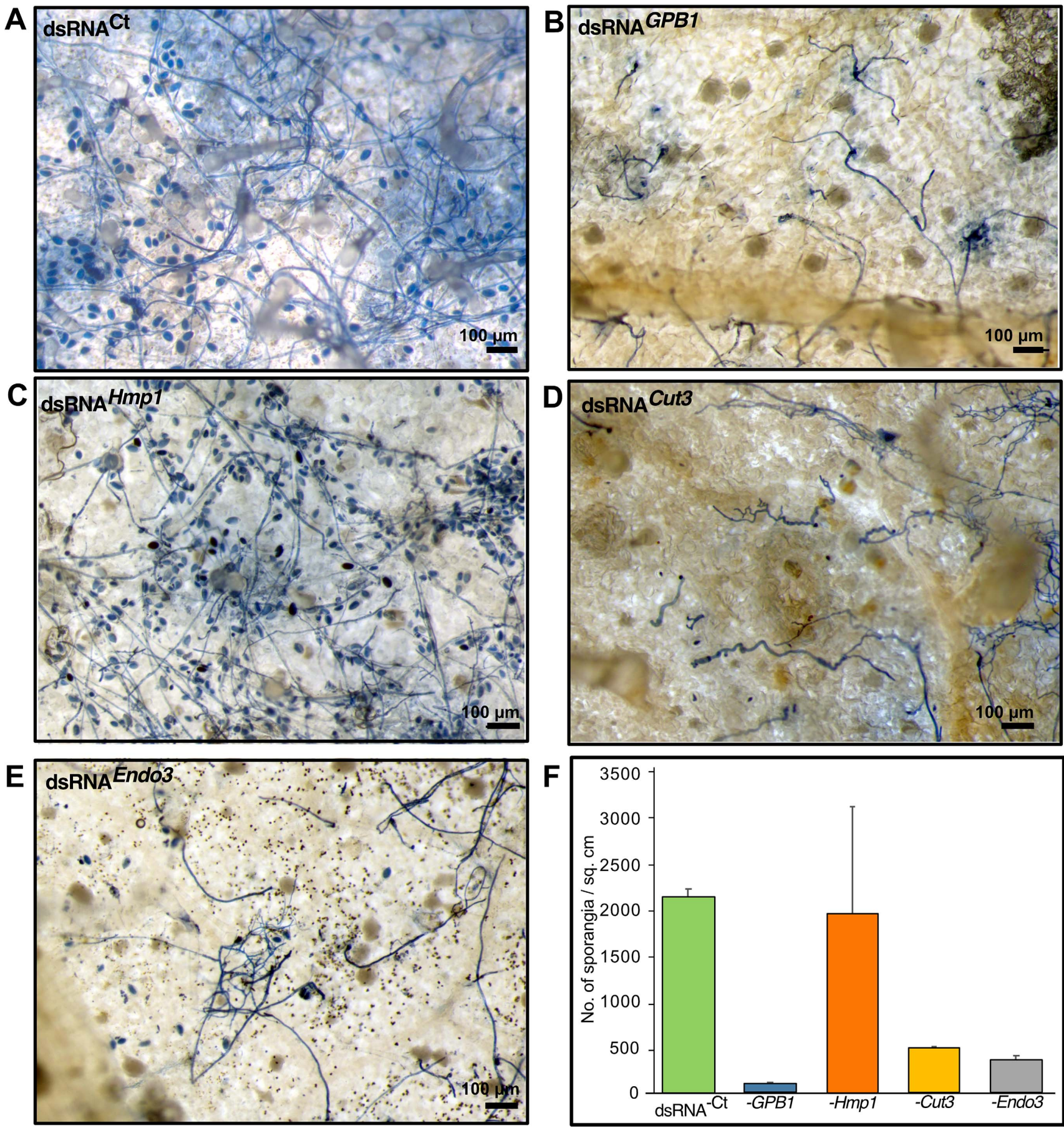

Fig. 4. Effect of spray-induced gene silencing on Phytophthora infestans infection morphology. A to E, Representative stereo microscope images showing the effect of different dsRNAs on $P$. infestans morphology on detached potato leaves; dsRNA ${ }^{\mathrm{C} t}$ (control), dsRNA ${ }^{P i G P B I}\left(\mathrm{G}\right.$ protein $\beta$-subunit), dsRNA ${ }^{P i E n d o 3}$ (endo-1,3[4]- $\beta$-glucanase), dsRNA ${ }^{\text {PiCut3 }}$ (cutinase), and dsRNA ${ }^{\text {PiHmpl }}$ (haustorial membrane protein). Leaves were stained with trypan blue followed by imaging on a Leica stereomicroscope with a $12 x$ objective. F, Average number of sporangia per $\mathrm{cm}^{2}$ of infection. Sporangia were counted manually from the images taken using the $12 \times$ objective. The graph represents mean sporangia count from three images taken from independent leaves. 
mRNA levels of the target genes and reduced infection levels were not observed (Qiao et al. 2021). There are methodological differences between Qiao et al. (2021) and our study, which may impact on the outcome of SIGS for P. infestans, such as in the mode of application of dsRNAs used on leaves and the inoculum concentration.

Our findings provide proof of concept for SIGS applications to control potato late blight and other Phytophthora diseases. However, a variety of parameters remain to be optimized to improve the efficacy of SIGS against $P$. infestans. First, uptake of dsRNA could be improved through the addition of adjuvants to the dsRNAs to increase permeability into $P$. infestans. We attempted to address this by addition of $10 \mathrm{mM}$ mannitol to the dsRNA solution, which boosted dsRNA uptake by sporangia, evidenced by higher cy3 fluorescence (Supplementary Fig. S3). Second, RNAs are notoriously labile, so improvements to dsRNA persistence on plant surfaces would be advantageous. To date, clay nanosheets have been proven to extend the lifetime of exogenously applied dsRNAs on plants (Mitter et al. 2017). Third, while SIGS has potential to control foliar disease development, preparation of artificial dsRNA is a costly procedure, and alternative methods of preparation need to be developed to make it cost-effective. Fourth, further studies such as risk assessment of SIGS application on the host plants and the surrounding environment would provide valuable information for the development of SIGS as a safe, sustainable, and socially acceptable tool for controlling plant diseases.

Data availability. All gene sequences used in this study have been obtained from NCBI GenBank; accession numbers are given in the text of the article. Primers used in this study are available as supplementary material.

\section{LITERATURE CITED}

Ah-Fong, A. M. V., Kim, K. S., and Judelson, H. S. 2017. RNA-seq of life stages of the oomycete Phytophthora infestans reveals dynamic changes in metabolic, signal transduction, and pathogenesis genes and a major role for calcium signaling in development. BMC Genomics 18:198.

Avrova, A. O., Boevink, P. C., Young, V., Grenville-Briggs, L. J., van West, P., Birch, P. R. J., and Whisson, S. C. 2008. A novel Phytophthora infestans haustorium-specific membrane protein is required for infection of potato. Cell. Microbiol. 10:2271-2284.

Boevink, P. C., Birch, P. R. J., Turnbull, D., and Whisson, S. C. 2020. Devastating intimacy: The cell biology of plant-Phytophthora interactions. New Phytol. 228:445-458

Boevink, P. C., Birch, P. R. J., and Whisson, S. C. 2011. Imaging fluorescently tagged Phytophthora effector proteins inside infected plant tissue. Methods Mol. Biol. 712:195-209.

Brouwer, H., Coutinho, P. M., Henrissat, B., and de Vries, R. P. 2014. Carbohydrate-related enzymes of important Phytophthora plant pathogens. Fungal Genet. Biol. 72:192-200.

Cai, Q., Qiao, L., Wang, M., He, B., Lin, F. M., Palmquist, J., Huang, Da, S., and Jin, H. 2018. Plants send small RNAs in extracellular vesicles to fungal pathogen to silence virulence genes. Science 360:1126-1129.

Fernández-Bautista, N., Domínguez-Núñez, J., Moreno, M. M., and Berrocal-Lobo, M. 2016. Plant tissue trypan blue staining during phytopathogen infection. Bio Protoc. 6.

Ghildiyal, M., and Zamore, P. D. 2009. Small silencing RNAs: an expanding universe. Nat. Rev. Genet. 10:94-108.

Hannon, G. J. 2002. RNA interference. Nature 418:244-251.

Huang, C. Y., Wang, H., Hu, P., Hamby, R., and Jin, H. 2019. Small RNAs-big players in plant-microbe interactions. Cell Host Microbe 26: 173-182.

Jahan, S. N., Åsman, A. K. M., Corcoran, P., Fogelqvist, J., Vetukuri, R. R., and Dixelius, C. 2015. Plant-mediated gene silencing restricts growth of the potato late blight pathogen Phytophthora infestans. J. Exp. Bot. 66: 2785.

Judelson, H. S., and Blanco, F. A. 2005. The spores of Phytophthora: Weapons of the plant destroyer. Nat. Rev. Microbiol. 3:47-58.

Kagda, M. S., Martínez-Soto, D., Ah-Fong, A. M. V., and Judelson, H. S. 2020. Invertases in Phytophthora infestans localize to haustoria and are programmed for infection-specific expression. MBio 11:1-17.

Kalyandurg, P. B., Tahmasebi, A., Vetukuri, R. R., Kushwaha, S. K., Lezzhov, A. A., Solovyev, A. G., Grenville-Briggs, L. J., and Savenkov, E. I. 2019. Efficient RNA silencing suppression activity of potato mop-top virus $8 \mathrm{~K}$ protein is driven by variability and positive selection. Virology 535:111-121.

Kamoun, S., Furzer, O., Jones, J. D. G., Judelson, H. S., Ali, G. S., Dalio, R. J. D., Roy, S. G., Schena, L., Zambounis, A., Panabières, F., Cahill, D., Ruocco, M., Figueiredo, A., Chen, X.-R., Hulvey, J., Stam, R., Lamour, K., Gijzen, M., Tyler, B. M., Grünwald, N. J., Mukhtar, M. S., Tomé, D. F. A., Tör, M., van den Ackerveken, G., McDowell, J., Daayf, F., Fry, W. E., Lindqvist-Kreuze, H., Meijer, H. J. G., Petre, B., Ristaino, J., Yoshida, K., Birch, P. R. J., and Govers, F. 2015. The top 10 oomycete pathogens in molecular plant pathology. Mol. Plant Pathol. 16:413-434.

Koch, A., Biedenkopf, D., Furch, A., Weber, L., Rossbach, O., Abdellatef, E., Linicus, L., Johannsmeier, J., Jelonek, L., Goesmann, A., Cardoza, V., McMillan, J., Mentzel, T., and Kogel, K. H. 2016. An RNAi-based control of Fusarium graminearum infections through spraying of long dsRNAs involves a plant passage and is controlled by the fungal silencing machinery. PLoS Pathog. 12:e1005901.

Koch, E., and Slusarenko, A. 1990. Arabidopsis is susceptible to infection by a downy mildew fungus. Plant Cell 2:437-445.

Latijnhouwers, M., and Govers, F. 2003. A Phytophthora infestans G-protein $\beta$ subunit is involved in sporangium formation. Eukaryot. Cell 2:971-977.

Leesutthiphonchai, W., Vu, A. L., Ah-Fong, A. M. V., and Judelson, H. S. 2018. How does Phytophthora infestans evade control efforts? Modern insight into the late blight disease. Phytopathology 108:916-924.

Malone, C. D., and Hannon, G. J. 2009. Small RNAs as guardians of the genome. Cell 136:656-668.

Miao, J., Cai, M., Dong, X., Liu, L., Lin, D., Zhang, C., Pang, Z., and Liu, X. 2016. Resistance assessment for oxathiapiprolin in Phytophthora capsici and the detection of a point mutation (G769W) in PcORP1 that confers resistance. Front. Microbiol. 7:1-14.

Miao, J., Li, X., Lin, D., Liu, X., and Tyler, B. M. 2018. Oxysterolbinding protein-related protein 2 is not essential for Phytophthora sojae based on CRISPR/Cas9 deletions. Environ. Microbiol. Rep. 10: 293-298

Mitter, N., Worrall, E. A., Robinson, K. E., Li, P., Jain, R. G., Taochy, C., Fletcher, S. J., Carroll, B. J., Lu, G. Q., and Xu, Z. P. 2017. Clay nanosheets for topical delivery of RNAi for sustained protection against plant viruses. Nat. Plants 3:16207.

Nowara, D., Schweizer, P., Gay, A., Lacomme, C., Shaw, J., Ridout, C., Douchkov, D., Hensel, G., and Kumlehn, J. 2010. HIGS: host-induced gene silencing in the obligate biotrophic fungal pathogen Blumeria graminis. Plant Cell 22:3130-3141.

Ospina-Giraldo, M. D., Griffith, J. G., Laird, E. W., and Mingora, C. 2010a. The CAZyome of Phytophthora spp.: A comprehensive analysis of the gene complement coding for carbohydrate-active enzymes in species of the genus Phytophthora. BMC Genomics 11:525.

Ospina-Giraldo, M. D., McWalters, J., and Seyer, L. 2010b. Structural and functional profile of the carbohydrate esterase gene complement in Phytophthora infestans. Curr. Genet. 56:495-506.

Pasteris, R. J., Hanagan, M. A., Bisaha, J. J., Finkelstein, B. L., Hoffman, L. E., Gregory, V., Andreassi, J. L., Sweigard, J. A., Klyashchitsky, B. A., Henry, Y. T., and Berger, R. A. 2016. Discovery of oxathiapiprolin, a new oomycete fungicide that targets an oxysterol binding protein. Bioorg. Med. Chem. 24:354-361

Qiao, L., Lan, C., Capriotti, L., Ah-Fong, A., Nino Sanchez, J., Hamby, R., Heller, J., Zhao, H., Louise Glass, N., Judelson, H. S., Mezzetti, B., Niu, D., and Jin, H. 2021. Spray-induced gene silencing for disease control is dependent on the efficiency of pathogen RNA uptake. Plant Biotechnol. J.

Raychaudhuri, S., and Prinz, W. A. 2010. The diverse functions of oxysterolbinding proteins. Annu. Rev. Cell Dev. Biol. 26:157-177.

San Miguel, K., and Scott, J. G. 2016. The next generation of insecticides: dsRNA is stable as a foliar-applied insecticide. Pest Manag. Sci. 72:801809.

Schepers, H. T. A. M., Kessel, G. J. T., Lucca, F., Förch, M. G., van den Bosch, G. B. M., Topper, C. G., and Evenhuis, A. 2018. Reduced efficacy of fluazinam against Phytophthora infestans in the Netherlands. Eur. J. Plant Pathol. 151:947-960.

van Wolfswinkel, J. C., and Ketting, R. F. 2010. The role of small noncoding RNAs in genome stability and chromatin organization. J. Cell Sci. 123:1825-1839.

Vetukuri, R. R., Avrova, A. O., Grenville-Briggs, L. J., Van West, P., Söderbom, F., Savenkov, E. I., Whisson, S. C., and Dixelius, C. 2011. Evidence for involvement of Dicer-like, Argonaute and histone deacetylase proteins in gene silencing in Phytophthora infestans. Mol. Plant Pathol. 12:772-785. 
Wang, M., Weiberg, A., Lin, F. M., Thomma, B. P. H. J., Da Huang, H., and Jin, H. 2016. Bidirectional cross-kingdom RNAi and fungal uptake of external RNAs confer plant protection. Nat. Plants 2:16151.

Weiberg, A., Wang, M., Lin, F. M., Zhao, H., Zhang, Z., Kaloshian, I., Huang, H. Da, and Jin, H. 2013. Fungal small RNAs suppress plant immunity by hijacking host RNA interference pathways. Science 342:118-123.

Whisson, S. C., Avrova, A. O., van West, P., and Jones, J. T. 2005. A method for double-stranded RNA-mediated transient gene silencing in Phytophthora infestans. Mol. Plant Pathol. 6:153-163.
Whisson, S. C., Boevink, P. C., Wang, S., and Birch, P. R. 2016. The cell biology of late blight disease. Curr. Opin. Microbiol. 34:127135.

Yan, S., Ren, B., Zeng, B., and Shen, J. 2020. Improving RNAi efficiency for pest control in crop species. Biotechniques 68:283-290.

Zerillo, M. M., Adhikari, B. N., Hamilton, J. P., Buell, C. R., Lévesque, C. A., and Tisserat, N. 2013. Carbohydrate-active enzymes in Pythium and their role in plant cell wall and storage polysaccharide degradation. PLoS One 8:e72572. 